\title{
Genomics and health care
}

\author{
How genomics medicineis translated into better health care largely depends on how physicians handle \\ thisinformation
}

$\mathrm{L}$ ast autumn, scientists at Duke University (Raleigh, NC, USA) publicized their discovery of a gene whose mutation causes cerebral cavernous malformations (CCM), a rare, inherited and deadly brain disease. The finding means that a test can now be developed to identify patients before they become symptomatic, which would allow them to be monitored and possibly treated using surgery. Just a few days later, deCODE Genetics in Reykjavik, Iceland, announced that they had found two susceptibility genes for obesity, adding to their portfolio of genes involved in stroke, schizophrenia and other disorders. Such announcements that yet another susceptibility gene has been discovered are on the rise and hit the headlines almost daily as researchers around the world identify more and more genes and genetic variations with a role in a wide variety of diseases and disorders. With these announcements comes hope that the discoveries could help to speed up the design of treatments.

But even finding the genes responsible for single-gene diseases that are more common than CCM, such as cystic fibrosis and Huntington's disease, or susceptibility genes for Alzheimer's disease, has not yet helped scientists to find better treatments. What the research has created, however, is a complex web of legal, social and ethical problems for researchers, patients and physicians.
Should a patient be tested for a disease for which there is no treatment? What if someone is found to be susceptible to a complex disease, such as hypertension, lung cancer or diabetes; will, can and should that imply that he or she has to modify his or her lifestyle? M ust a patient inform his or her family of genetic test results? What, if anything, might change a physician's responsibility to keep a patient's information confidential? Should drugs be sold only to people with specific genotypes? Moreover, the possibility of

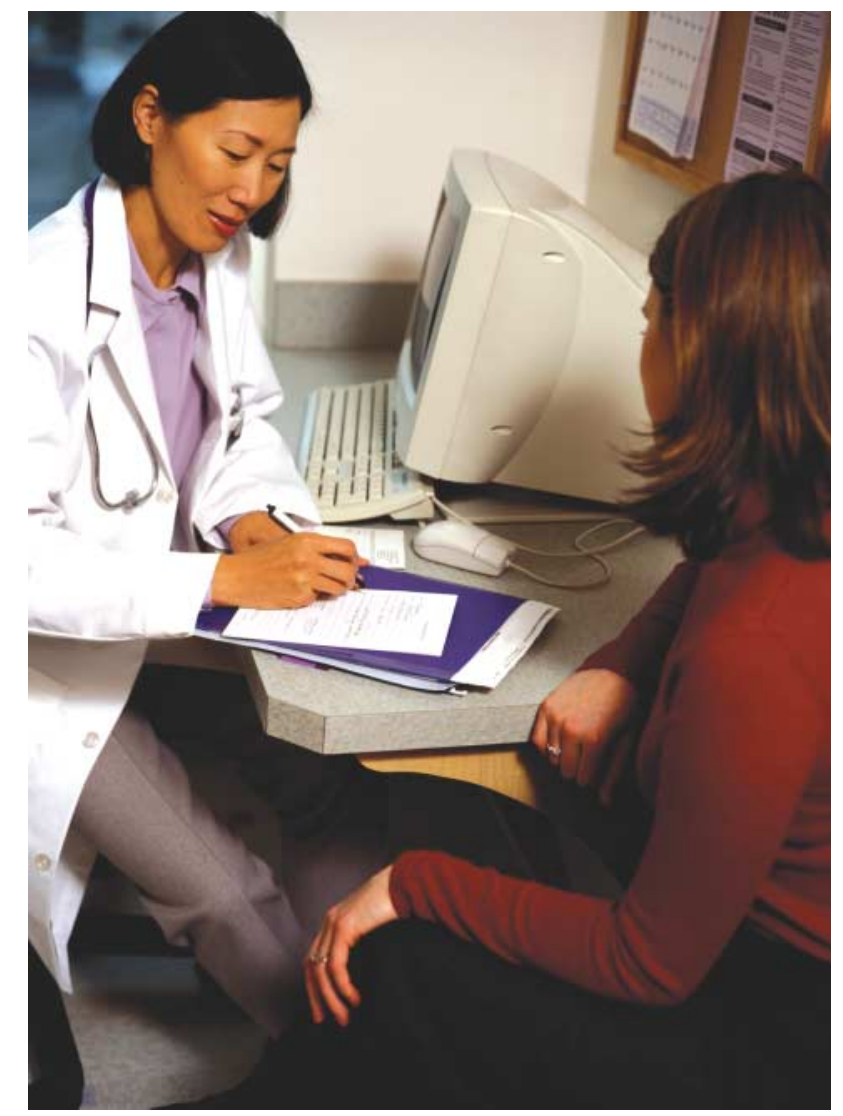

genetic discrimination in the workplace and in health insurance, social stigmatization, and the implications for public health and the physician-patient relationship are all issues raised by geneticsbased healthcare. Few definitive answers have been found for any of them, nor have laws been changed yet.

"Genomics presents particular challenges with respect to clinicians' ethical and professional responsibilities, including the appropriate use of genomic information in the health care setting," commented Ellen W right Clayton, Professor of Pediatrics and Law, and Director of the Center of Genetics and Health Policy at Vanderbilt University (Nashville, TN, USA) (Clayton, 2003). It will be the physicians, as the patient's primary contact with the health care system, who will be faced with the new possibilities and the ethical and legal challenges raised by genomic medicine. A recent report by the British Nuffield Council on Bioethics suggests that the benefits of genetic research may indeed be accompanied by unintended negative consequences (Nuffield Council on Bioethics, 2003). It flags four areas of particular concern: patient consent and confidentiality; resources in health carecertain technologies might lower the cost of developing and delivering medicines, but others might drive it up; equity-more people might fall into categories for which effective drugs are not developed owing to insufficient financial incentives; and control-who decides whether a patient takes a pharmacogenetic test?

$\mathrm{n}$ the meantime, genomics is generating fear. "People tend to see genetic information as more definitive and predictive than other types of data, in the sense that 'you cannot change your genes' and that 'genes tell all about your future,'" Clayton noted. "Such genetic determinism is an oversimplification and does not take into account the nature of biologic systems .... Nor is the connection between genes and health necessarily direct," she added. This 'genetic essentialism'-viewing people as the sum of their genes while ignoring their lives and histories and believing that there is a one-to-one correlation between a mutation and illness-is at the heart of the current fears, Clayton stated. The fear that 


\section{science $\&$ society}

genetic testing may be misused is indeed well-founded in some cases. For example, Burlington Northern Santa Fe Railroad (BNSF, Fort Worth, TX, USA) tested employees, who were seeking disability payments for carpal tunnel syndrome, for a mutation connected to hereditary neuropathy and pressure palsies without their knowledge or consent. After it became public, the federal Equal Employment O pportunity Commission stopped the testing in 2002 and BNSF settled claims brought by employees. BNSF clearly displayed unethical behaviour, particularly in testing its employees without their consent. In contrast, genetic testing of employees working in dangerous settings or exposed to potentially harmful substances is certainly beneficial for both the employer and the employee. "The answer, however, is not simply to forbid employers to use genetic information or to require genetic testing," Clayton commented (Clayton, 2003). Rather, it is necessary to determine how the use of genetic information fits within a broader framework of anti-discrimination regulations, she believes.

M

ost of the ethical and legal problems created by the new tools and technologies in genomic medicine will manifest at the interface between patients and physicians. Genetic testing might well complicate the physician-patient relationship, because although the physician is sworn to confidentiality, that duty is not absolute. As physicians must already report infectious diseases to public health authorities, the question arises whether they should also report risks found by a test-not necessarily a genetic test- to relatives in danger. Such questions of patient privacy and confidentiality versus public and family health have not yet been resolved and it is not clear whether new laws will be an effective solution. In the light of recent proposed legislation, doctors in some countries are advised not to share health data that could identify patients without either first obtaining their explicit consent or totally anonymizing the data, according to Chris Verity from the Child Development Centre at Addenbrooke's Hospital in Cambridge, UK (Verity \& Nicoll, 2002). Verity and his co-author Angus Nicoll, Director of the Communicable Disease Surveillance Centre in London,

\section{It will bethe physicians, as the patient's most important contact with the health care system, who will befaced with thenew possibilities and ethical and legal challenges of genomic medicine}

UK, fear that these restrictions would compromise surveillance activities essential for the protection of individuals and public health. Ideally, physicians should reach a consensus among themselves and issue guidelines, so that cases do not reach the courts. "Because the development of tests to assess risk is likely to outpace the ability to reduce risk, an ongoing dialogue involving clinicians and policymakers will be needed to develop a consensus about their appropriate clinical use," commented Wylie Burke, Professor and Chair of the Department of Medical History and Ethics at the University of Washington in Seattle, WA, USA (Burke, 2002).
In theory, genetics and genomics technologies can improve public health, but even this is debatable, according to Clayton. "Targeted public health interventions pose particular risks to group members who are not actually at risk or affected but who find themselves suddenly officially labelled by government actions," she said, referring to the stigma experienced by Haitians when they were identified as being at high risk for HIV/AIDS. Clayton believes, as do others, that using race in research and public health practice creates more complex and intractable problems than ignoring race. And even with testing, some groups still do not receive appropriate care. Some Ashkenazi Jews, who participated in relatively large numbers in early testing for BRCA1/2 genes and colon cancer, now fear being stigmatized because of the discovery that mutations of the cancer-predisposing genes BRCA1/2 and APC (familial adenomatous polyposis coli) are highly prevalent in this group (Clayton, 2002). However, pharmacogenomics will eventually identify groups of

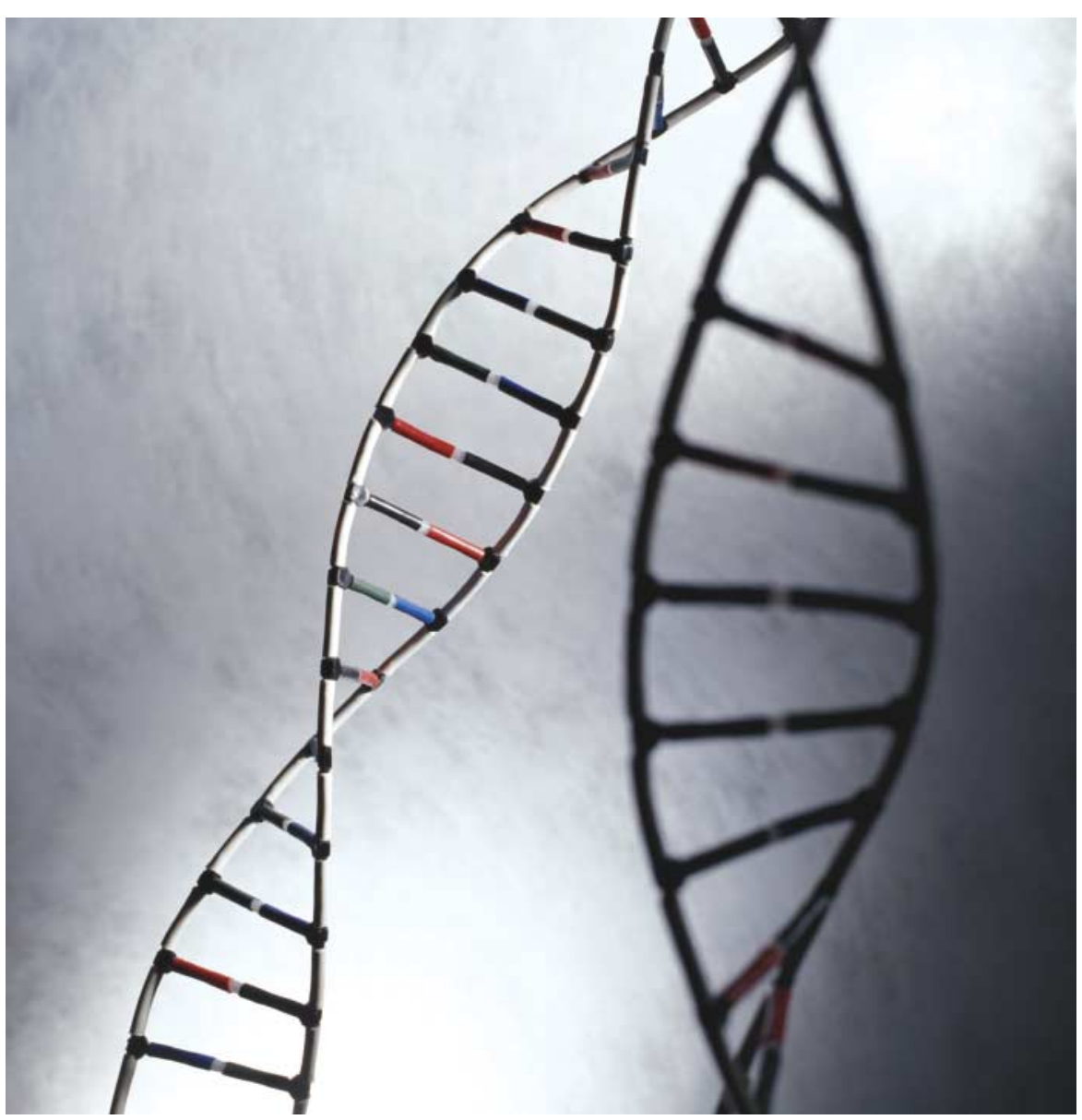




\section{As physicians must already report infectious diseases to public health authorities, the question arises whether they should also report risks found by a test- not necessarily a genetic test- to relatives in danger}

people who are more or less susceptible to certain drugs, with implications for the development, testing and marketing of medications. Some drugs, such as the antihypertension drug BiDil (NitroMed, Bedford, M A, USA), are al ready being marketed to certain racial groups on the basis of pharmacogenomic data. And more and more pharmaceutical companies are conducting pharmacogenetic research to pinpoint those for whom their drugs will be most effective, to prevent adverse side reactions and to streamline clinical trials for safety and efficiency. In addition, the US Food and Drug Administration (Rockville, MD, USA) issued a guidance last $\mathrm{N}$ ovember encouraging drug makers to conduct pharmacogenomic tests during development, and clarified how it would evaluate the resulting data.

$\mathrm{n}$ the end, however, it is up to the primary physician to make sense of genetic tests and to devise a treatment strategy. Tests for risk factors yield complex results that often must be interpreted by knowledgeable physicians who take into account the patient's behaviour and environmental interactions. For instance, genetic testing for factor $V$ Leiden-a relatively common disorder that affects $1-5 \%$ of Americans-can predict an eightfold increased risk of venous thrombosis and a 12-30\% lifetime risk of blood clot if a person is heterozygous for the gene mutation. But the test does not tell the whole story, noted Burke. "O ver half of the events associated with this condition occur when other risk factors-like surgery, bed rest, use of oral contraceptives-are also present," he said, and it is up to the physician to be aware of and explain this complex interplay to the patient. The usefulness of such tests in a clinical setting will also depend on whether specific, effective interventions to reduce the risk exist, Burke added.
Knowledge of one's genetic susceptibility to disease could actually be harmful to health by reducing one's motivation to pursue protective measures, Burke also suggested. In fact, a growing body of research shows that new or improved genetic knowledge does not necessarily motivate people to change behaviour or lifestyle. Theresa Marteau, Professor of Health Psychology at King's College, London, UK, and Caryn Lerman, Professor of Psychiatry at the University of Pennsylvania (Philadelphia, PA, USA) and principal investigator of the Transdisciplinary Tobacco Use Research Center partnership with Georgetown University Medical Center (Washington, DC, USA), examined the relationship between genetic risk and behavioural change in several studies and found that simply telling people that they are at risk for developing a disease is rarely enough to motivate them to change their behaviour (M arteau \& Lerman, 2001). Women who were told that they had an inherited predisposition to breast cancerbut not given a genetic test- showed a modest increase in rates of adherence to mammography. Women found to be carriers of BRCA1/2 mutations, however, did not become more adherent to mammography after they learned their test results. And "little is known about the effect testing has on other health behaviours, such as smoking, activity levels, and diet," Marteau and Lerman wrote. Similarly, some smoking studies showed that genetic risk information might not lead to changes in behaviour even when a definitive risk-reduction strategy exists. Moreover, Marteau and Lerman also discovered that only a minority of such interventions to induce change are effective. "O verall, the current evidence suggests that providing people with DNAderived information about risks to their health does not increase motivation to change behaviour beyond that achieved with non-genetic information," they concluded. "For some people, genetic information may even reduce motivation to change behaviour."

\section{... a growing body of research shows that new or improved genetic knowledge does not necessarily motivate people to change behaviour or lifestyle}

Another study even showed that public perceptions of genetic-based disease and testing tended to be negative. The study investigated the reaction of parents to the results of a genetic test for predisposition to familial hypercholesterolaemia and whether they perceived the results as a genetic problem or not. If they did, the condition was seen as more uncontrollable and more threatening. Conversely, those who regarded the test as a mere detection of higher cholesterol levels saw the condition as either familial or dietary in origin, and therefore controllable and less threatening. "These pilot data raise questions about the extent to which assessing disease risks by DNA analysis may result in a sense of fatalism, adversely affecting motivation to change behaviour and reduce risks," Marteau and her co-workers commented (Senior et al, 1999). Conversely, they noted that it is important to ensure that those found not to be at increased risk do not develop a false sense of security, "feeling invulnerable to the adverse effects of their risky behaviour." There is no doubt among scientists that genomic medicine will eventually generate great health benefits both for the individual and the public. But its practical application, particularly in the physician's office, still lags behind the research in the scientists' laboratories.

\section{REFEREN CES}

Burke W (2002) Genetic testing. N Engl J Med 347: 1867-1875

Clayton EW (2002)The complex relationship of genetics, groups, and health: what it means for public health. J Law M ed Ethics 30: 290-297

Clayton EW (2003) Ethical, legal, and social implications of genomic medicine. N Engl J Med 349: 562-569

M arteau TM, Lerman C (2001) Genetic risk and behavioural change. Br M ed J 322: 1056-1059

Nuffield Council on Bioethics (2003) Pharmacogenetics: Ethical Issues. N uffield Council on Bioethics, London, UK

SeniorV, M arteau TM, Peters TJ (1999) Will genetic testing for predisposition for disease result in fatalism? A qualitative study of parents responses to neonatal screening for familial hypercholesterolaemia. Soc Sci M ed 48: 1857-1860

Verity C, Nicoll A (2002) Consent, confidentiality, and the threat to public health surveillance. Br M ed J 324: 1210-1213

\section{Vicki Brower \\ doi:10.1038/sj.embor.7400086}

